\title{
SUSTAINABLE AND DURABLE MATERIAL FOR PAVEMENT CONSTRUCTION
}

\author{
ROMEL NANO GEORGEES, RAYYA A. HASSAN, \\ PIRATHEEPAN JEGATHEESAN \& ROBERT P. EVANS \\ Faculty of Science, Engineering and Technology, Swinburne University of Technology, Australia
}

\begin{abstract}
Urban and rural mobility (including freight) in Australia is heavily dependent on road use. Road pavements in both environments are mostly flexible and comprise a thin asphaltic seal over granular bases and sub-bases on natural ground or select fill layers. To achieve sustainability in road construction and minimize the use of virgin aggregates, there is a need to enhance the properties of existing or low quality materials to meet the desired performance criteria. Polymer-based additives have shown to improve strength and durability characteristics of granular and subgrade pavement materials. Furthermore, these polymer additives have a lower carbon footprint than common traditional cement-based stabilizers. In this study, a synthetic polyacrylamide-based additive (PAM) was used to stabilize three types of soil used in pavement construction. Unconfined compressive strength, erosion and abrasion tests were conducted to evaluate the performance of soils treated with PAM. The results did vary depending on soil type, but showed a significant overall increase in strength for all soil types. The results also showed improvements in erosion and abrasion resistance for all soils tested. This means that there is potential for using PAM-stabilized material to reduce pavement thickness in urban areas and for sealing unsealed forest roads.
\end{abstract}

Keywords: pavement materials, subbase, select fill, unconfined compressive strength, abrasion resistance, erosion resistance.

\section{INTRODUCTION}

State and federal governments within Australia are under pressure to design, build and maintain road infrastructure within the conservative funds available. Furthermore, the public are constantly demanding higher performing roads that are environmentally sustainable (via using more recycled materials or materials of marginal quality). This has created a focus on the development of innovative construction techniques that allow low quality local materials to be used in road pavement construction. This is particularly important in the urban environment where high quality aggregates are scarce and associated transport costs are high.

The stabilization of pavement materials using cementitious additives has proven to be a successful and reliable technique to increase the performance of pavement materials and prolong the service life of a pavement structure. It also has the ability to reduce the overall thickness of the structural base or subbase layers, thus providing a more economical design. Traditional cementitious stabilizers have been used in Australia to construct sealed and unsealed roads for over thirty-five years. They have shown to improve strength, workability, and durability. However, to be effective, large quantities of such additives are required as well as relatively long curing times. This translates into significant increases in construction time and associated costs. The other drawback of using a cementitious type additive is that it increases the risk of reflective cracking in the asphaltic surface layer [1], [2]. Therefore, the development of non-traditional stabilizers, such as polymers have gained significant attention recently as they have demonstrated an effectiveness in the field with regards to reducing permeability, increasing durability, and being non-time dependent during mixing and compaction, as well as being more environmentally sustainable [3], [4]. 


\section{BACKGROUND}

In Australia, polymers have been used by select contractors as a pavement material stabilizer or dust suppressant for unsealed roads [5]. However, polymers have not been fully accepted by the road construction industry as standard practice. The principal function of most of these polymers is to provide a distinctive hydrophobic feature to the treated layers to preserve an adequate dry strength for moisture-susceptible materials, in addition to providing a bonding action between particles [6]. Polyacrylamide (PAM), which is a hydrophilic polymer, has been used in the field of agriculture for nearly half a century due to its ability to increase infiltration and decrease irrigation-induced erosion [7]. Yet, until recently its use to stabilize pavement materials was very rare.

Yongfeng et al. [8] tested the effectiveness of a polyacrylamide-based additive on changing the engineering behaviour of a highly plastic clay soil with the aim of establishing the failure mode of the soil treated with PAM. It was concluded that the addition of PAM showed an increase in failure strain, which increased its flexibility. Another study was conducted by Georgees et al. [9] to investigate the potential improvement in engineering properties when the materials were treated with an anionic polyacrylamide-based additive. Different soil types were tested and the level of compaction was varied from modified compaction to higher compaction efforts depending on the soil type. The authors reported a variant significance in shear strength improvement, with a significant improvement in the unconfined compressive strength for granular soils and a moderate improvement for clayey soils.

The only available published study to evaluate the effect of PAM on the durability of pavement materials was performed in the field [10]. The study comprised of evaluating an unsealed road pavement after being stabilized with PAM. The treated pavement section was $400 \mathrm{~m}$ long and $8 \mathrm{~m}$ wide and comprised silty sand soil. Performance of the PAM-stabilized pavement was monitored over 18 months. It was found that the untreated pavement sections deteriorated rapidly over the first 12 months due to environmental and traffic conditions, whereas the treated sections maintained their structural integrity throughout the entire 18-month monitoring period. In particular, the surface of the untreated section developed into a rough and open texture with many loose particles, while the treated section showed a tighter texture with very few loose particles.

Due to the success of the abovementioned field trial, an extensive and systematic laboratory investigation was performed to assess the potential durability improvements of PAM-treated materials used for select fills or granular subbase materials. The additive used in this study was an "off-the-shelf" product that is currently available in Australia and has demonstrated positive results in the field. The improvement in strength helps in two aspects; first, it reduces the depth of pavement which is important when rehabilitating urban pavements to match existing levels of other civil infrastructure such as the kerb and channel of drainage system, and second, it increases the strength of the structural layer to withstand the stresses imposed on the foundation by construction traffic when the road is under construction. Furthermore, improvements in the abrasion and erosion resistance help to reduce dust generation from the wear action of traffic and loss of mass during the erosion action of rainfall.

\section{MATERIALS AND TESTING METHODS}

Three different types of soils from three different sites in Australia were selected and referred to herein as soils A, B and C. The samples had different particle size distribution with up to $20 \mathrm{~mm}$ aggregate size. The classification of these soils according to the unified soil 
classification system (USCS), along with grain size proportions and soil indices are tabulated Table 1.

The polymeric additive used in this study was a synthetic soluble anionic polyacrylamide (PAM), which is produced in granular form. The PAM has a moderate charge density of about $18 \%$ and a high molecular weight of typically $12-15 \mathrm{Mg} / \mathrm{mol}$. The product is a nontoxic water soluble material with a specific gravity of 0.8 and a $\mathrm{PH}$ value of 6.9 at $25{ }^{\circ} \mathrm{C}$. Samples for testing were provided by Earthco Project Ltd.

Physical properties of the three soils tested were drawn from a previous study by the authors [11]. Subsequently, unconfined compressive strength (UCS), erosion and abrasion resistance tests were undertaken in order to determine the shear strength property and sealing capacity of PAM, in terms of reducing abrasion due to traffic and water erosion actions.

Laboratory test samples were prepared in accordance with relevant Australian standards. The required amount of PAM was determined according to the supplier's recommendation, which was $0.002 \%$ by dry weight of the soil. After mixing the soil-water mixture, samples were kept in sealed plastic bags and stored at room temperature for 24 hours to allow even moisture distribution.

For the UCS test, specimens (treated and untreated) were compacted to maximum dry density at optimum moisture content. Specimens were compacted at compaction efforts of $3574 \mathrm{kNm} / \mathrm{m}^{3}$ for soil types $\mathrm{B}$ and $\mathrm{C}$, and $4595 \mathrm{kNm} / \mathrm{m}^{3}$ for soil type A, using 35 and 45 blows per layer, respectively.

Two sets of specimens (dry and soaked) per sample (both treated and untreated) were prepared for the UCS test. The first set of specimens was tested according to the dry test condition immediately after the dry back period was completed. This consisted of removing the cylindrical specimens from the split moulds after compaction and storing them in a curing room at a temperature of $25 \pm 3^{\circ} \mathrm{C}$ and relative humidity of $50 \pm 0.5 \%$ until the lowest moisture content was reached. This approach was adopted to simulate the potential effects of

Table 1: Properties of soil types A, B and C.

\begin{tabular}{|l|l|l|l|}
\hline Properties & Soil A & Soil B & Soil C \\
\hline \% gravel $(4.75 \mathrm{~mm}$ to $19.0 \mathrm{~mm})$ & 33.2 & 29.6 & 13.2 \\
\hline$\%$ sand $(0.075 \mathrm{~mm}$ to $4.75 \mathrm{~mm})$ & 56.8 & 46.4 & 36.8 \\
\hline$\%$ fines $(<0.075 \mathrm{~mm})$ & 10.0 & 24.0 & 50.0 \\
\hline \% clay $(<2 \mu \mathrm{m})$ & 0.75 & 2.75 & 13.5 \\
\hline Liquid limit (\%) & 22.2 & 23.8 & 31.4 \\
\hline Plastic limit (\%) & N/A & 12.8 & 15.1 \\
\hline Plasticity index (\%) & N/A & 11 & 16.3 \\
\hline Optimum moisture content $(\%)$ & 5.6 & 8.5 & 12.5 \\
\hline $\begin{array}{l}\text { Max dry density }\left(\mathrm{g} / \mathrm{m}^{3}\right) \\
\text { before adding PAM }\end{array}$ & 2.35 & 2.01 & 1.96 \\
\hline $\begin{array}{l}\text { Max dry density }\left(\mathrm{g} / \mathrm{m}^{3}\right) \\
\text { after adding PAM }\end{array}$ & 2.38 & 2.04 & 1.97 \\
\hline Soil classification $(\mathrm{USCS})$ & $(\mathrm{SP}-\mathrm{SM})^{1}$ & $(\mathrm{SC})^{2}$ & $(\mathrm{CL})^{3}$ \\
\hline $\begin{array}{l}{ }^{1} \text { Poorly-graded sand with silt. } \\
{ }^{2} \text { Clayey sand with gravel. } \\
{ }^{3} \text { Lean sandy clay with gravel. }\end{array}$ & & \\
\hline
\end{tabular}


the stabilizer on the predominant conditions rather than the worst conditions. Specimens were then sealed in thin plastic cling wrap and left for 14 days to insure an even distribution of moisture, as well as to normalize the curing time factor for both treated and untreated samples. Samples of the second set of specimens were sprayed with water containing dissolved PAM and left to dry back until a constant mass was reached. This procedure was used to simulate the sealing capacity of the polymer when used in the field, in which PAM is distributed evenly across the treated materials, but highly concentrated on the surface of the lift. These dried specimens were then subjected to a wet condition before being tested following the procedure outlined by Santoni et al. [12] (see Figs.1(a) and 1(b)). The only difference was the duration of soaking, in which a specimen was placed on its side in a $25.4 \mathrm{~mm}$ of water for 30 minutes rather than 15 minutes. After soaking, the specimen was left to drain for 5 minutes (to remove the excess water) before being tested via the UCS test.

Load versus deformation data was collected using a data acquisition system that was calibrated to load the specimen at a rate of $1 \mathrm{~mm}$ per minute. Thus, all specimens were tested under controlled strain conditions. The specimens were loaded either to the point where the load reached a maximum value and then decreased with increasing strain, or until $15 \%$ strain was reached [13].

The abrasion resistance test was performed according to the test method proposed by Sampson [14]. Here, soil samples were sieved to collect only particles less than or equal to $4.75 \mathrm{~mm}$ in diameter. The reason for selecting a maximum aggregate size of $4.75 \mathrm{~mm}$ was to eliminate the possibility of intermittent plucking of the coarse particles by the brush [15]. Test samples were prepared according to the earlier procedure mentioned for the UCS samples. The specimens were left to dry back until reaching a constant weight. At least three specimens per sample (treated and untreated) were prepared. The cylindrical specimens were tested up to 500 revolutions with the brush load of $2.2 \mathrm{~kg}$ on the side of the tested specimen. This was performed in two stages, each 250 revolutions, to reproduce the long-term traffic wear action in the laboratory [1] (Fig. 2(a)). The brushed specimens were then weighed and the loss of mass as a percentage of the original mass was recorded.

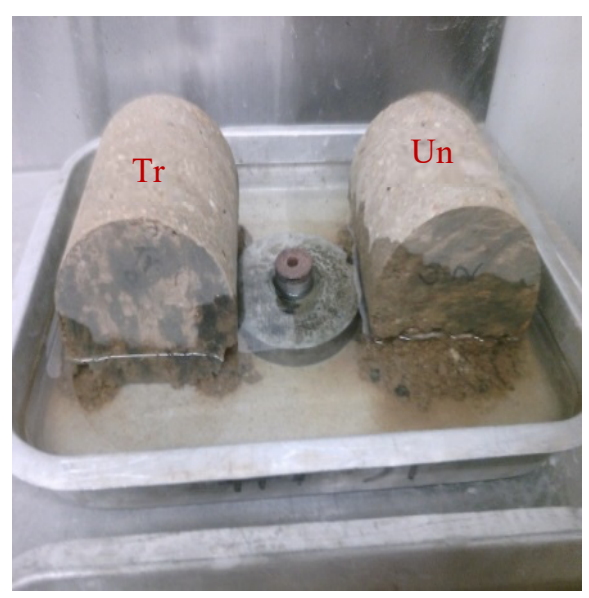

(a)

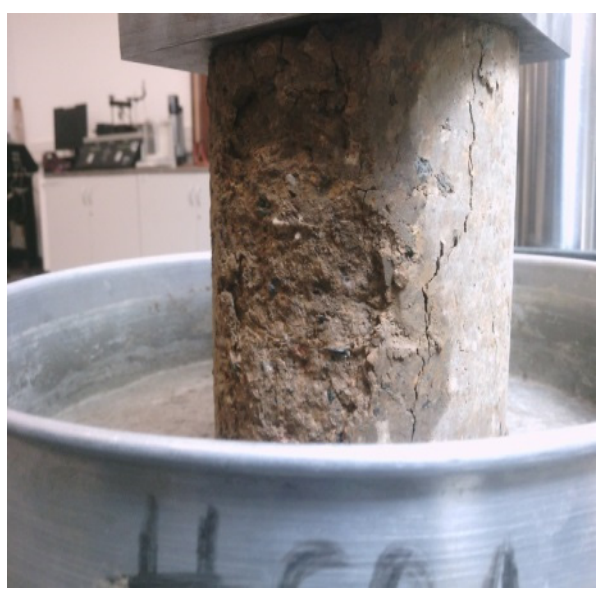

(b)

Figure 1: (a) Comparison of treated (Tr) and untreated (Un) soaked samples after 30 minutes; (b) Wet sample (treated or untreated) during the UCS test. 


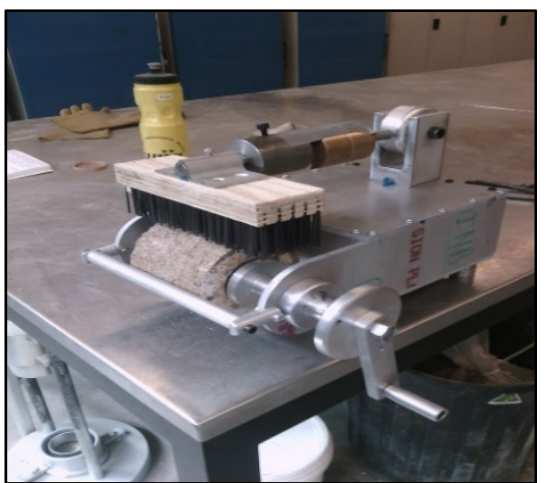

(a)

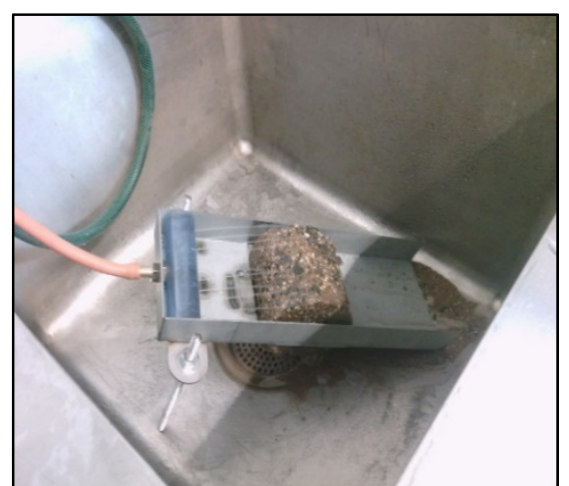

(b)

Figure 2: (a) Abrasion resistance apparatus; (b) Erosion resistance apparatus.

For the erosion resistance test, a method proposed by Jones and Ventura [16] was used. All the procedures described above for the abrasion resistance test were applied when preparing the samples, except that the maximum aggregate size was kept the same as the UCS samples. In addition, the treated specimens were also sprayed with water containing dissolved PAM and left to dry back until a constant mass was reached. After drying back, specimens were then positioned in the erosion apparatus and subjected to a constant head of one meter of water flow to simulate the water flow on the road surface (Fig. 2(b)). The specimens were subjected to a water flow for 5 minutes and then allowed to drain for 5 minutes. Specimens were then dried in an oven to a constant mass and the mass loss as a percentage to the original mass was recorded.

\section{RESULTS AND DISCUSSION}

The geotechnical properties of the three soil types used in this study are tabulated in Table 1. Sieve analysis and hydrometer test results showed that the soils had a wide range of gradations ranging from well to medium and poorly graded for soil types A, B and C respectively. More details and discussions on testing the physical properties of these soils can be found in [11].

The effect of using PAM on the dry unconfined compressive strength for the three soil types was assessed using the dry condition test, while the effect of PAM in retaining the strength after exposure to moisture was assessed using the wet condition test. The UCS values of the treated and untreated samples for the three soil types are presented in Fig. 3. It is worth noting that the strength values (treated and untreated samples) presented in the figure represent an average UCS value based on at least three specimens.

Fig. 3 shows a consistent increase in UCS for all soil types after being treated with PAM. For the dry strength test results, a significant increase in strength was observed in both treated soil types A (Gravel with silt and sand) and B (Clayey Gravel with sand), while only a moderate increase in strength was noted for treated soil type C (Clayey Sand with gravel). The increase in the dry UCS test was found to be 26.8, 19.4 and $11.6 \%$ respectively. From these results, it appears that the PAM additive was more effective at treating soil with less fine grained material as soil types A, B and C comprised of 10, 24 and 50\% fine content 


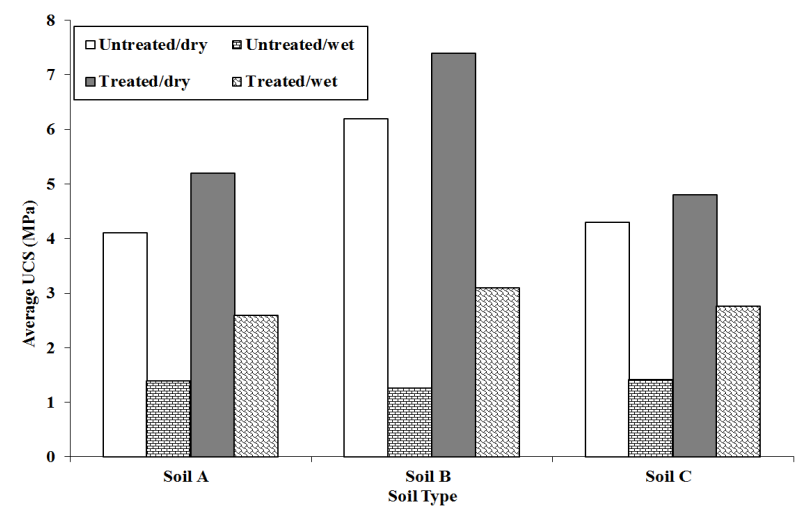

Figure 3: Average wet and dry UCS test results for the treated and untreated samples for soil types A, B and C.

(i.e. passing the $75 \mu \mathrm{m}$ sieve) respectively. Furthermore, the majority of the fine particles in soil type A were determined to be silt while the fine particles in soil types B and C were determined to be clay.

Fig. 3 also illustrates moisture susceptibility of the samples when tested under wet conditions. Here, the treated and untreated samples revealed reductions in UCS values for all three types of soils. The loss in strength was critical at an average of $65.8,79.6$ and $67.0 \%$ for all untreated soil types A, B and C respectively. However, all three soil types treated with PAM showed a lower loss in strength at 49.5, 57.3 and $42.4 \%$ respectively. This implies that treating a soil with PAM provides a significant resistance to moisture deterioration, particularly for soils that contain highly plastic fines (soil type C). It is believed that the polymer better sealed the soil's pores in a manner that prevented water permeating into the inner pores. The mechanism preventing water entering the pores is related to increasing the viscosity of the water during contact between the polymer and soil surface. Thus, impeding water ingress and preserving the dry strength of the pavement material.

Furthermore, the retained strength of the treated samples, when tested under wet conditions, was dramatically higher when compared with the untreated samples. Soil types A and $C$ showed an increase in wet strength of 85.6 and $94.3 \%$ respectively compared to the untreated ones. Surprisingly, soil type B exhibited a $146.6 \%$ increase in strength when treated with PAM.

Fig. 4 demonstrates the effect of PAM to increase the abrasion resistance. It is worth noting that the mass loss (in grams) for the samples (treated and untreated) presented in this figure are average values based on three specimens per sample.

For the first 250 revolutions of abrasion, the mass loss was greatest for soil type A and least for soil type C. The mass loss was strongly dependent on the amount of clay fines present in the soil as the abrasion resistance was in the order of soil type A > soil type B > soil type C. A similar trend was found for the treated materials for all tested soils, but with less intensity. Fig. 4 also demonstrates a regular increase in abrasion resistance for the treated samples when compared to the untreated samples. Abrasion resistance, at the end of 250 revolutions, was dramatically increased in soil types $\mathrm{A}$ and $\mathrm{C}$ with an average of 45.1 and $60.9 \%$ respectively, whereas soil type B only showed a $38.1 \%$ increase in abrasion resistance. Increasing the brush load revolution to 500 did not change the trend of the samples and the mass loss for soil types A, B and C was 48, 23.5 and 59.3\% respectively. 


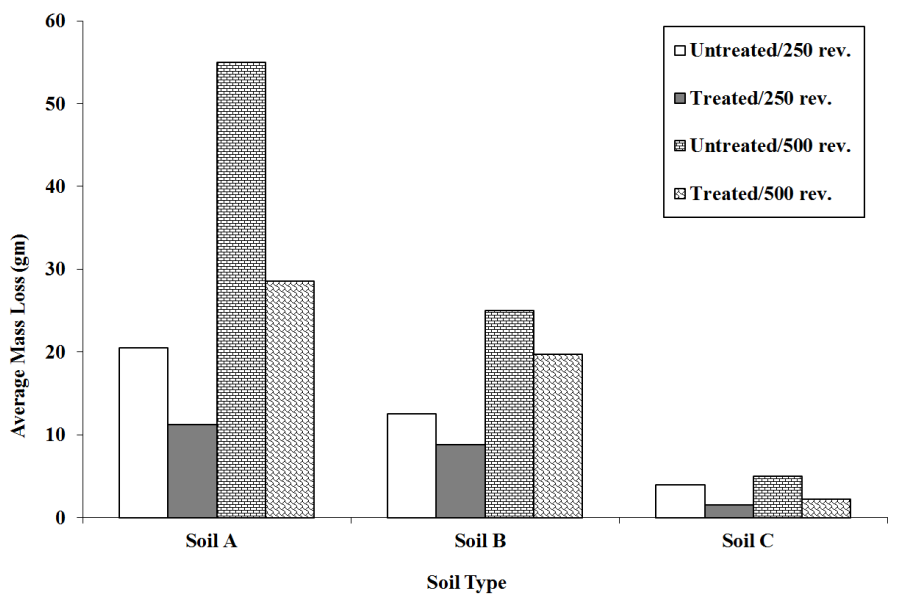

Figure 4: Abrasion resistance test results (mass loss) for treated and untreated samples of soil types $\mathrm{A}, \mathrm{B}$ and $\mathrm{C}$.

The capacity of PAM to protect the compacted specimens from water flow was also tested. Using an erosion test, Fig. 5 captures the effect the PAM additive had on reducing erosion. In this figure, three specimens per sample (treated and untreated) were tested and the average values of mass loss (gm) have been presented.

The difference in mass loss (due to erosion) between the untreated and PAM treated samples for the three soil types was clearly evident in Fig. 5. The greatest mass loss was recorded for the treated sample soil type $\mathrm{C}$ with an erosion reduction of $94.5 \%$, which was followed by 79.3 and $70.3 \%$ for soil types A and B respectively. This reduction in mass loss correlated well with the amount of clay present within the tested soils (i.e. 1, 2.75 and $13.5 \%$ for soil types A, B and C respectively). As expected, the polymer increased the erosion resistance of the materials tested, which in turn increases the stability of the pavement layer after prolonged exposure to the rainfall during construction stages.

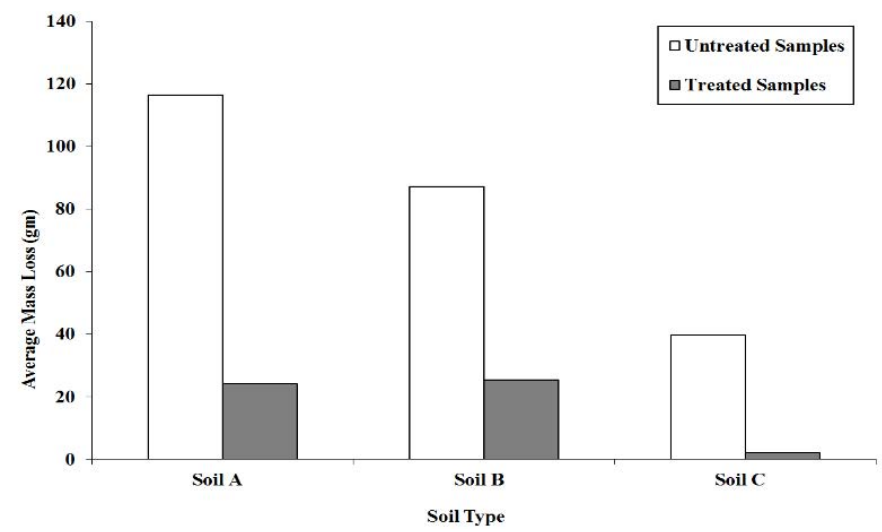

Figure 5: Erosion resistance test results for treated and untreated samples (with PAM) of soil types A, B and C. 


\section{CONCLUSION}

From laboratory testing, the following has been concluded when using PAM as a stabilizing additive to treat unbound pavement materials:

- An increase in dry and wet strength was noted for all soils treated with PAM. However, this increase in strength did vary depending on soil type. The greatest strength increase was noted for soils with the least amount of fines and clay content. Furthermore, for the wet condition strength test, the reduction in strength (due to wetting) was significantly less for all treated soils. Thus, the addition of PAM improved soils' resistance to moisture absorption. The average recorded gain in dry strength for the treated samples was between 11.6 and $26.8 \%$, while the loss in strength of the PAM treated samples (due to wetting) was considerably less than the untreated samples (i.e. 42.4 to $57.3 \%$ compared with 63.7 to $79.6 \%$ ).

- An increase in the resistance to abrasion was measured between 29.2 and $62.5 \%$ for all soil types treated with PAM. Unlike the strength test results, there was no evidence that soil type was a factor.

- An increase in the resistance to erosion was measured between 70.9 to $94.5 \%$ for all soil types treated with PAM. Here, the addition of PAM was more effective for the soils with greater fines and clay content. This was a significant result.

Overall, these results indicate that PAM is a promising stabilizing additive for sustainably improving the performance of pavement materials and subgrade soils with the potential of reducing pavement thickness. Further, the improved durability and resistance to erosion of treated material facilitates staged construction to reduce traffic delay in urban environment. This is in addition to the feasibility of using PAM for sealing unsealed forest roads.

\section{ACKNOWLEDGEMENT}

The authors would like to acknowledge the contribution of Earthco projects company, particularly Mr. Mark Holding, for providing the stabilizer additive and soils for this research.

\section{REFERENCES}

[1] Judy, F. et al., Stabilized sub-bases for heavily trafficked roads in the Philippines. Journal of the Eastern Asia Society for Transportation Studies, 6, pp. 1274-1285, 2005.

[2] Rodway, B., Polymer stabilisation of clayey gravels. Proceedings for 20th ARRB Conference, Melbourne. 2001.

[3] Wilmot, T.D., Applications for stabilisation in pavement construction and rehabilitation. Malaysian Road Conference, Kuala Lumpur, Malaysia, 1994.

[4] Camarena, S., Sustainable road maintenance and construction utilising new technologies. International Public Works Conference, Darwin, Northern Territory, Australia, 2013.

[5] Austroads, Guide to Pavement Technology: Part 4L: Stabilising Binders, Austroads: Australia, 2006.

[6] Wilmot, T. \& Rodway, B., Stabilised pavements-selecting the additive: Cementitious, Polymer or Bitumen. Australian Civil Engineering Transactions, 42, p. 27, 2000.

[7] Sojka, R. et al., Polyacrylamide in agriculture and environmental land management. Advances in Agronomy, 92, pp. 75-162, 2007.

[8] Yongfeng, D. et al., Strength and permeability of cemented soil with PAM. Grouting and Deep Mixing 2012, Louisiana ASCE, New Orleans, 2012. 
[9] Georgees, R.N. et al., Effect of the use of a polymeric stabilizing additive on unconfined compressive strength of soils. Transportation Research Record: Journal of the Transportation Research Board, 2473, pp. 200-208, 2015.

[10] Andrews, R. \& Sharp, K., A protocol for conducting field trials for best value management of unsealed roads. 24th ARRB Conference, Australia, 2010.

[11] Georgees, R.N. et al., An evaluation of performance related properties for granular pavement materials using a polyacrylamide additive. International Journal of Pavement Engineering, pp. 1-11, 2016.

[12] Santoni, R.L., Tingle, J.S. \& Webster, S.L., Stabilization of silty sand with nontraditional additives. Transportation Research Record: Journal of the Transportation Research Board, 1787(1), pp. 61-70, 2002.

[13] ASTM, Standard Test Method for Unconfined Compressive Strength of Cohesive Soil, in ASTM D2166, American Society for Testing Materials: West Conshohocken, PA, 2008.

[14] Sampson, L., Development of the Mechanical Wet/Dry Brushing Test for the Durability Testing of Stabilized Materials, Transportek, CSIR (Confidential Report C/DPVT/3.1): Pretoria, SA, 1988.

[15] Jones, D., Development of performance-based tests for nontraditional road additives. Transportation Research Record: Journal of the Transportation Research Board, 1989(1), pp. 142-153, 2007.

[16] Jones, D. \& Ventura, D., Development of fit-for-purpose certification testing for nontraditional road additives. Phases I-III. Contract report: CR-2003/34, Division of Roads and Transport Technology, CSIR: Pretoria, SA, 2003. 